\title{
AVALIAÇÃO DE DUAS ROTINAS DE CARBONIZAÇÃO EM FORNOS RETANGULARES ${ }^{1}$
}

Tatiana Paula Marques de Arruda², Alexandre Santos Pimenta ${ }^{3}$, Benedito Rocha Vital ${ }^{4}$, Ricardo Marius

Della Lucia ${ }^{4}$ e Fidel Candano Acosta ${ }^{2}$

\begin{abstract}
RESUMO - Este estudo objetivou avaliar o desempenho de fornos retangulares no processo de carbonização, envolvendo duas rotinas de carbonização. As rotinas analisaram a influência de tatus e câmaras de combustão externa no processo de carbonização em quatro fornos retangulares instrumentados com termopares para acompanhamento da temperatura, bem como o balanço de massa e energia do sistema. A lenha utilizada na carbonização foi o clone A08, híbrido do cruzamento entre Eucalyptus grandis e Eucalyptus urophylla, com idade de 7 anos e comprimento da lenha de $3 \mathrm{~m}$. Foram realizadas oito carbonizações em cada rotina. De acordo com os resultados, verificou-se que a rotina 2, caracterizada pelo uso das câmaras de combustão externa, foi mais eficiente no controle da carbonização; a instrumentação do forno é uma técnica viável, mas que requer ajustes para caracterizar, com precisão, o fenômeno da carbonização. No balanço de massa e energia, verificou-se que as perdas foram maiores que os ganhos em produção, para lenha com elevados teores de umidade.
\end{abstract}

Palavras-chave: Fornos retangulares, Carbonização de madeira e Produção de carvão vegetal.

\section{EVALUTION OF TWO CARBONIZATION ROUTINES IN RECTANGULAR KILNS}

\begin{abstract}
The objective of the present work was to evaluate the performance of rectangular kilns in the carbonization process involving two carbonization routines. The routines analyzed the influence of air inlets and external combustion chambers on the carbonization process in four rectangular kilns equipped with thermo pairs for following temperature and mass and energy balance of the system as well. The firewood used in carbonization was the A08 clone, Eucalyptus grandis and Eucalyptus urophylla hybrid, at 7 years of age and 3 meters of wood length. Eight carbonizations were made for each routine. According to the results, it was verified that routine 2 , which uses external combustion chambers, was more efficient for the carbonization control; Kiln instrumentation is a viable technique, but it requires adjustments for a precise characterization of the carbonization phenomenon. For mass and energy balance, it was verified that production losses were greater than profits for high moisture content firewood.
\end{abstract}

Keywords:Charcoal production, Rectangular kilns and Wood carbonization.

\section{INTRODUÇÃO}

O carvão vegetal é um insumo amplamente utilizado pelas siderúrgicas brasileiras como agente redutor, principalmente por se tratar de matéria-prima renovável e pouco poluente quando comparada aos combustíveis fósseis. Conforme Botrel et al. (2007), o carvão tem posição de destaque na economia brasileira e, principalmente, na economia do Estado de Minas Gerais, uma vez que o seu consumo representa $66,7 \%$ do total de carvão vegetal consumido no país. A produção de carvão vegetal, porém, é feita em fornos de alvenaria pouco desenvolvidos, onde o controle da carbonização

\footnotetext{
${ }^{1}$ Recebido em 31.10.2008 e aceito para publicação em 20.04.2011.

${ }^{2}$ Universidade do Estado de Mato Grosso, UNEMAT, Brasil. E-mail: <tatianarruda@ig.com.br>e < fidel.candano@yahoo.com.br>.

${ }^{3}$ Departamento de Agropecuária da Universidade Federal do Rio Grande do Norte, UFRN, Brasil. E-mail: <alexandrepimenta@bricarbras.com.br>.

${ }^{4}$ Departamento de Engenharia Florestal, Universidade Federal de Viçosa, UFV, Brasil. E-mail: <bvital@ufv.br>e < rdlucia@ufv.br>.
} 
depende fundamentalmente do conhecimento do operador, que se baseia em fatores subjetivos, como colorações da fumaça e temperatura das paredes sentida pelo tato das mãos. Entretanto, os fornos de alvenaria para carbonização de madeira sofreram grandes modificações, que objetivaram maior eficiência e produtividade, em função da crescente demanda no consumo de carvão vegetal como fonte energética. O maior dimensionamento proposto ao forno retangular permitiu a mecanização nas etapas de carregamento e descarregamento, minimizando tempo e mão de obra (ZUCHI, 2000) e a sua instrumentação, o acompanhamento térmico do processo de carbonização.

Este estudo objetivou avaliar o desempenho de fornos retangulares no processo de carbonização envolvendo duas rotinas. As rotinas de carbonização analisaram a influência de tatus e câmaras de combustão externa nesse processo, analisando-se: a) os parâmetros do processo: umidade da lenha, tempo de ignição, tempo de carbonização, temperatura média, taxa de aquecimento, temperatura final, tempo de resfriamento, rendimentos volumétricos e gravimétricos, análise química imediata, poder calorífico e tiço; b) eficiência do sistema de monitoramento térmico na aquisição de temperaturas; c) perfil térmico do forno no processo de carbonização e resfriamento; e d) balanço de massa e energia.

\section{MATERIAL E MÉTODOS}

Os dados utilizados para desenvolver este trabalho foram obtidos de fornos retangulares de 160 estéreos, construídos em alvenaria, com dimensões de $13 \mathrm{~m}$ x 4 m x 4 m, contendo câmaras de combustão externa, chaminé e claraboia, situados na cidade de Açailândia, no Estado do Maranhão. O experimento foi conduzido em quatro fornos retangulares em rotina operacional industrial, durante o período de seis meses. Na primeira rotina foram conduzidas oito carbonizações, com controle de ar no sistema por meio das câmaras de combustão externa e abertura de 11 tatus nas bases das paredes do forno, sendo seis tatus na parede sem chaminé e cinco tatus na parede com chaminé. $\mathrm{Na}$ segunda rotina foram conduzidas oito carbonizações com controle da entrada de ar no sistema somente por meio das câmaras de combustão externa. A Figura 1 representa esquematicamente o forno retangular, com o posicionamento dos tatus e a instrumentação no forno.

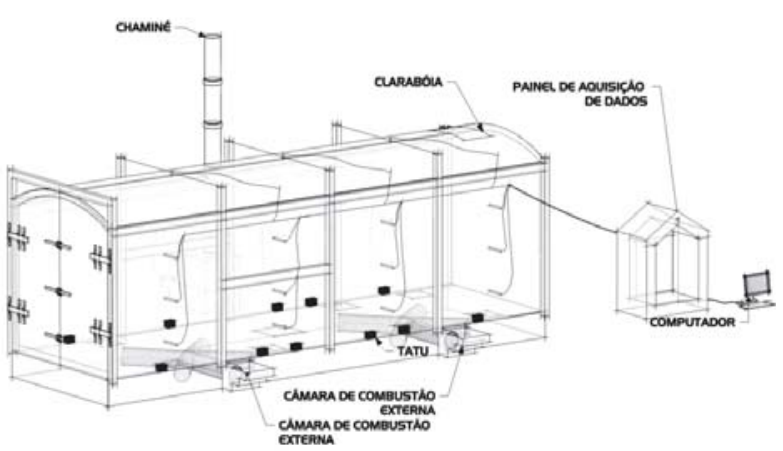

Figura 1 - Representação esquemática do forno retangular, com o posicionamento dos tatus e a instrumentação no forno.

Figure 1 - Schematic representation of the rectangular kiln, with air inlets positioning and kiln instrumentation.

O forno foi instrumentado com o objetivo de obter o perfil térmico do processo de carbonização, em escala industrial, com a inserção de termopares do tipo PT100, nas paredes laterais e no teto do forno. As temperaturas registradas no processo foram convertidas por meio de um painel de controle em sinais elétricos padronizados e enviados ao computador. Com o programa "Web Server WS $10^{\circledR}$, foi criada uma interface dos dados adquiridos no processo, em páginas HTML dinâmicas, o que permitiu visualizar as temperaturas em tempo real, utilizando um navegador de Internet.

A lenha utilizada na carbonização foi o clone A08, híbrido do cruzamento entre Eucalyptus grandis e Eucalyptus urophylla, com idade de 7 anos. O comprimento da lenha foi de $3 \mathrm{~m}$ e o diâmetro médio, de $17,5 \mathrm{~cm}$. A lenha foi pesada no caminhão antes do descarregamento na Unidade de Produção de Redutor (UPR), com o auxílio de balança rodoviária. Foi determinado o volume de lenha enfornada em todas as carbonizações; medindo-se a altura da pilha de lenha no box (estrutura para depósito da lenha) a cada $2 \mathrm{~m}$ de distância, em ambos os lados da pilha, para compor a média aritmética da altura. O resultado da multiplicação das medidas (altura x comprimento da pilha x comprimento da lenha (largura)) foi considerado o volume em estéreos de lenha. Para determinação da umidade e densidade foram utilizadas as Normas da ABNT NBR 7190/97 e NBR 11941/03, respectivamente. Foram retiradas aleatoriamente 15 peças como amostras de cada carbonização. De cada peça foram retirados 3 discos de aproximadamente $3 \mathrm{~cm}$ de espessura sendo dois 
a $20 \mathrm{~cm}$ das extremidades e um no centro. E de cada disco foram retiradas cunhas opostas para determinação da umidade e densidade. As amostras foram secas em estufa a $105^{\circ} \mathrm{C} \pm 3{ }^{\circ} \mathrm{C}$, por $24 \mathrm{~h}$, e pesadas. Os dados das temperaturas foram arquivados da página HTML, fornecida pelo programa WS 10, em intervalos de $1 \mathrm{~h}$, após o início do processo de carbonização, e lançados no programa “Excel XP ${ }^{\circledR}$ ”. Em todas as carbonizações foram registradas a data e hora do início do processo, com o objetivo de determinar os tempos de carbonização e de resfriamento. O tempo gasto na ignição foi determinado pela temperatura média dos 27 pontos de monitoramento, quando esta fosse superior ou igual a $45^{\circ} \mathrm{C}$.

Por meio do registro das temperaturas foi identificada a temperatura média com a temperatura máxima entre as médias atingidas na carbonização e a taxa de aquecimento. Para traçar o perfil térmico nos processos de carbonização e de resfriamento, foi utilizada a média geral dos 27 pontos de leitura de temperatura, medidos no forno. Para avaliar a qualidade do carvão, foram coletadas amostras de diferentes alturas e posição na pilha de carvão, com um total de 12 amostras por carbonização. O procedimento de amostragem e preparação da amostra foi executado conforme a norma ABNT NBR 6923/81. Os procedimentos utilizados para a análise química imediata foram os das normas ASTM D-1762-64 e na ABNT NBR 8112/83. Na aplicação da última, foram adotadas, como normas complementares, a NBR 5734/83 e NBR 6923/81. O carvão foi pesado em caminhão do tipo gaiola com volume conhecido e determinada a densidade a granel. O rendimento gravimétrico foi determinado por meio da relação massa de carvão seco produzido por massa de lenha seca e o rendimento volumétrico, determinado pela relação volume de lenha carbonizada por volume de carvão produzido. O poder calorífico superior do carvão foi calculado com base na média de oito carbonizações realizadas para a rotina 1 e oito para a rotina 2 , sendo determinados numa bomba calorimétrica adiabática, sistema PARR. Os passos utilizados no cálculo do poder calorífico superior foram realizados conforme a Norma ASTM D-2015-66.

O balanço de massa e energia foi calculado considerando-se as médias das carbonizações realizadas para as duas rotinas, ou seja, a média em quilos de lenha em base seca, utilizando-se, para a vaporização da água: energia maior que 30\% (600 kcal/kg - água livre) e energia menor que 30\% (824 kcal/kg - água adesão) (SKAAR, 1972); (KOLLMANN et al., 1975) e (PANSHIN ; DEZEEUW, 1970).

A partir dos resultados, pode-se verificar a viabilidade do sistema, em perdas e ganhos de energia.

Para determinação do peso da água, utilizou-se a equação 1 .

$$
P a=P l u ́-\frac{P l u ́}{(1+U)}
$$

em que:

$\mathrm{Pa}=$ peso de água $(\mathrm{kg})$;

Plú = peso de lenha úmida (kg); e

$\mathrm{U}=$ umidade da lenha (\%).

Para determinação da água livre, utilizou-se a equação 2 .

$$
P a l=P a x \frac{(U-0,3)}{U}
$$

em que:

$\mathrm{P}_{\mathrm{al}}=$ peso da água livre $(\mathrm{kg})$;

$\mathrm{Pa}=$ peso da água $(\mathrm{kg})$; e

$\mathrm{U}=$ umidade da lenha (\%).

Para determinação da água de adesão, utilizou-se a equação 3 .

$$
\mathrm{P}_{\text {aa }}=\mathrm{P}_{\mathrm{a}}-\mathrm{P}_{\mathrm{al}}
$$

em que:

$\mathrm{P}_{\mathrm{aa}}=$ peso da água de adesão $(\mathrm{kg})$;

$\mathrm{P}_{\mathrm{a}}=$ peso de água $(\mathrm{kg}) ; \mathrm{e}$

$\mathrm{P}_{\mathrm{al}}=$ peso de água livre $(\mathrm{kg})$.

Para determinação da energia consumida pela água, determinou-se a energia consumida com água livre e água de adesão, respectivamente, por meio das equações 4 e 5 .

$$
\mathrm{E}_{\mathrm{al}}=\mathrm{P}_{\mathrm{al}} * \mathrm{E}_{\mathrm{e}, 30 \%}
$$

em que:

$\mathrm{E}_{\mathrm{al}}=$ energia da água livre ( $\left.\mathrm{kcal} / \mathrm{kg}\right)$; 
$\mathrm{P}_{\mathrm{al}}=$ peso da água livre $(\mathrm{kg})$; e

$\mathrm{E}_{\mathrm{e}{ }^{30 \%}}=$ energia consumida da água livre (600 kcal/kg).

$$
\mathrm{E}_{\mathrm{aal}}=\mathrm{P}_{\text {aa }} * \mathrm{E}_{<30 \%}
$$

em que:

$\mathrm{E}_{\text {аа }}=$ energia da água de adesão ( $\left.\mathrm{kcal} / \mathrm{kg}\right)$;

$\mathrm{P}_{\text {aа }}=$ peso da água de adesão $(\mathrm{kg})$; e

$\mathrm{E}_{<30 \%}=$ energia consumida da água de adesão (824 kcal/kg).

Para as avaliações estatísticas, foram realizadas duas rotinas de carbonização com oito repetições cada rotina. Os dados foram submetidos à estatística descritiva para obtenção dos resultados médios e à análise de variância.

\section{RESULTADOS}

Os resultados da análise de variância dos parâmetros avaliados no processo de carbonização estão apresentados na Tabela 1.

\section{DISCUSSÃO}

\subsection{Produção de carvão vegetal}

Com relação aos parâmetros, umidade da lenha, tempo de ignição, temperatura média, taxa de aquecimento, rendimento gravimétrico, umidade do carvão e cinzas, foram observadas diferenças estatísticas significativas, indicando resultados diferenciados entre as rotinas estudadas. Nota-se a influência direta do teor de umidade da lenha com os parâmetros rendimento gravimétrico, tempo de ignição, temperatura média e taxa de aquecimento, no processo de produção de carvão vegetal. Com o elevado teor de umidade da lenha, a taxa de aquecimento é muito lenta, a temperatura máxima média é inconstante devido ao excesso de vapor de água liberado e consequentemente aumenta o tempo de ignição e de carbonização. Nas rotinas 1 e 2, obtiveram-se rendimentos gravimétricos de 23,8\% e 28,4\%, respectivamente, com teores de umidade da lenha de $66 \%$ para a rotina 1 e de $48 \%$ para a rotina 2, comprovando a teoria de Valente (1986) de que a redução desses rendimentos se deve ao consumo de parte da carga de lenha para evaporar a água, o que diminui o rendimento em base seca. Os fornos retangulares com capacidade volumétrica de 190 estéreos da empresa Vallourec \& Mannesmann Florestal obtêm rendimento de aproximadamente 35\% (CAMPOS,
2000). Com base nesses dados, observou-se baixo rendimento gravimétrico obtido na produção de carvão vegetal devido à elevada umidade da lenha.

A umidade da lenha não interferiu nos parâmetros umidade do carvão e cinzas, mas sim nos fatores externos, como provável incêndio na carga do carvão, com consequente uso de água para apagá-lo, o que provocou aumento na umidade do carvão, e, em relação à diferença nos teores de cinzas, isso se deveu à contaminação por material estranho, como pedra, terra e outros elementos, o que comprometeu a avaliação desses parâmetros.

Não houve diferenças estatísticas significativas para os parâmetros tempo de carbonização, temperatura final, tempo de resfriamento, rendimento volumétrico, matérias voláteis, carbono fixo e volume de tiço, indicando que para esses parâmetros avaliados não houve diferenças significativas entre as rotinas. Porém, o coeficiente de variação para o volume de tiço foi elevado devido ao seu reaproveitamento em outras fornadas (bateladas) para produzir carvão vegetal. A densidade da madeira foi de $530 \mathrm{~kg} / \mathrm{m}^{3}$.

\subsection{Perfil térmico da carbonização}

Os perfis térmicos da carbonização nas rotinas 1 e 2 estão caracterizados nas Figuras 2 e 3, respectivamente.

Na rotina 1 (Figura 2), o tempo médio de carbonização foi de 10 dias (240 h), com uma média de cinco dias (120 h) para secagem da lenha. A fase de secagem da lenha não é claramente evidenciada, mas, de acordo com Almeida (1982), encontra-se nos intervalos de temperaturas entre 110 e $200{ }^{\circ} \mathrm{C}$.

Já na rotina 2 (Figura 3) o tempo médio de carbonização foi de aproximadamente nove dias (210 h), com uma média de quatro dias (95h) para secagem dalenha. Observou-se que o tempo médio de carbonização nas rotinas 1 e 2 foi diferenciado, por aproximadamente $24 \mathrm{~h}$, nos processos, o que se deveu à diferença de umidade da lenha utilizada nas rotinas. A lenha carbonizada com teores de umidades superiores a 30\% proporciona desperdício de matéria-prima, aumento no tempo de carbonização, dificuldade no controle do sistema e queda na produção, além de comprometer a qualidade do carvão vegetal. Essas afirmações foram comprovadas por Valente (1986). 
Tabela 1 - Resultados da análise de variância dos parâmetros avaliados: umidade da lenha (U\%), tempo de ignição (TI), tempo de carbonização (TC), temperatura média máxima (TPMM), taxa de aquecimento (TX), temperatura final (TF), tempo de resfriamento (TR), rendimento volumétrico (RV), rendimento gravimétrico (RG), umidade do carvão (UC), matérias voláteis (MV), cinzas (CZ), carbono fixo (CF) e tiço.

Table 1 - Results of the analysis of variance for the parameters analyzed: firewood moisture content (U\%), ignition time (TI), carbonization time (TC), mean maximum temperature (TPMM), heating rate (TX), final temperature (TF), cooling time (TR), volumetric yield (RV), gravimetric yield (RG), charcoal moisture (UC), volatile materials (MV), ash (CZ), fixed carbon (CF) and unburned wood residuals (tiço).

\begin{tabular}{lccccccccccccccccc}
\hline FV & GL & U & TI & TC & TPMM & TX & TF & TR & RV & RG & UC & MV & CZ & CF & TIÇO \\
\hline Tratamento & 1 & $1.260,25$ & 60,06 & 4 & $16.512,25$ & 0,25 & $3.540,25$ & 0,25 & 0,35 & 83,11 & 46,65 & 07 & 0,84 & 0,62 & 152,89 \\
& & $* *$ & $* *$ & n.s & $* *$ & $*$ & n.s & n.s & n.s & $* *$ & $*$ & n.s & $* *$ & n.s & n.s \\
Resíduo & 14 & 47,2 & 8,45 & 4,78 & $1.663,48$ & 0,55 & $1.847,68$ & 1,34 & 0,57 & 8,56 & 10,76 & 25,01 & 0,6 & 24,67 & 40,91 \\
Média & - & 57,25 & 9,81 & 9,25 & 269,75 & 0,82 & 234,12 & 5,25 & 1,75 & 26,07 & 6,44 & 22,73 & 0,57 & 76,7 & 7,17 \\
CV $_{\text {exp }}(\%)$ & - & 12,05 & 29,63 & 23,65 & 15,12 & 28,61 & 18,36 & 22,04 & 13,59 & 11,21 & 50,95 & 22 & 42,81 & 6,48 & 89,24 \\
\hline
\end{tabular}

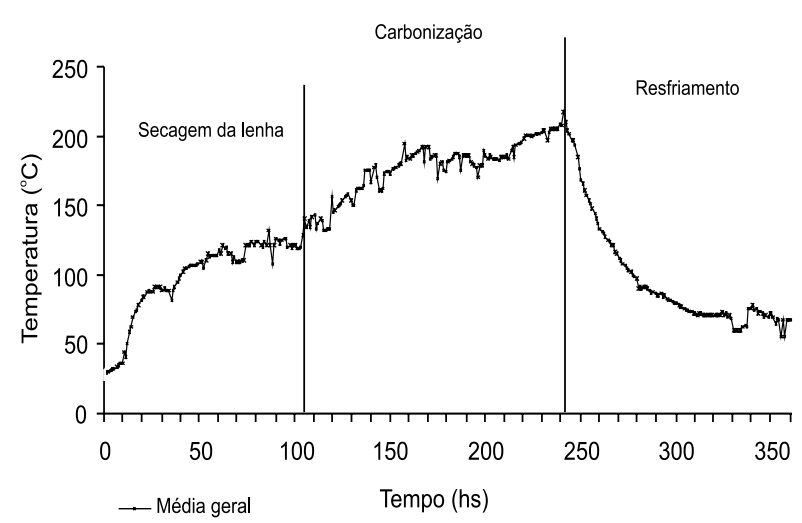

Figura 2 - Perfil térmico médio do processo de carbonização na rotina 1.

Figure 2 -Average thermic profile of the carbonization process for routine 1.

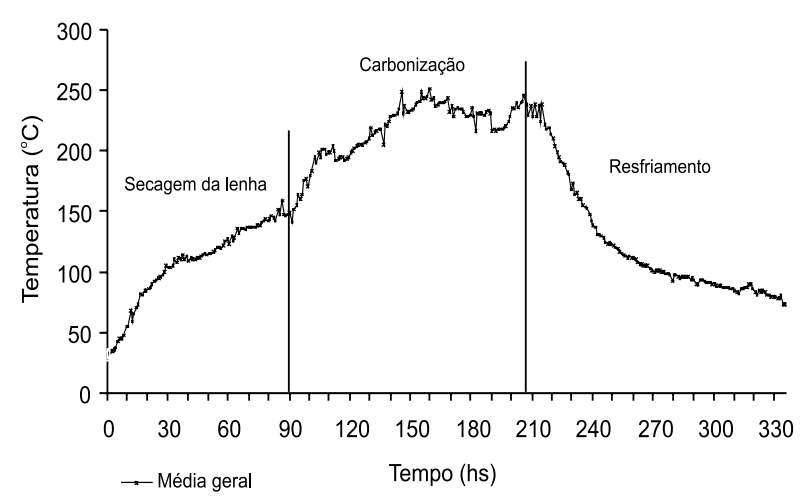

Figura 3 - Perfil térmico médio do processo de carbonização na rotina 2 .

Figure 3-Average thermic profile of the carbonization process for the routine 2 .
No processo de resfriamento, o tempo médio para as rotinas foi de cinco dias. Campos (2000), em seus estudos, obteve um tempo de nove dias para o resfriamento de um forno retangular com capacidade volumétrica para 190 estéreos.

\subsection{Balanço de massa e energia}

Os resultados apresentados na Tabela 2 permitem avaliar a conversão de biomassa (lenha) em energia (carvão vegetal) para as duas rotinas de carbonização nos fornos retangulares de 160 estéreos.

Foi observada perda de energia de $9 \%$ na secagem da lenha; essa energia despendida para evaporação da água da lenha correspondeu a $14 \mathrm{~m}$ de carvão (MDC); se levar em conta o preço atual do metro do carvão vegetal em $\mathrm{R} \$ 180,00$, pode-se considerar uma perda de R\$2.520,00 em carvão vegetal, somente na secagem da lenha. A energia prevista no final do processo, na forma de carvão vegetal, foi inferior a $50 \%$. Entretanto, se forem convertidos os $36 \%$ de energia produzida em quantidade de carvão vegetal, isso corresponderia a aproximadamente 56 MDC, o equivalente a $\mathrm{R} \$ 10.080,00$.

Para tanto, as perdas de energia no sistema, através das paredes, fumaça, aquecimento da lenha, queima do carvão, resfriamento do carvão etc. foram de $55 \%$. Se for considerada a energia total consumida e convertendo-a em carvão vegetal, isso apresentaria um montante de 86 MDC, o equivalente a R\$15.480,00. Ao analisar o sistema, verificou-se que as perdas de 9\% (14 MDC) somadas aos 55\% (86 MDC) correspondem a 100 (MDC), sendo significativamente 
Tabela 2 - Balanço de massa e energia despendida e resultante no processo de carbonização em fornos retangulares de 160 estéreos.

Table 2 - Mass and energy balance spent and resulting from the carbonization process in 160 stereos rectangular kilns.

\begin{tabular}{|c|c|c|c|c|c|c|c|c|}
\hline \multirow[t]{2}{*}{ Tipo } & \multicolumn{2}{|c|}{ Massa (kg) } & \multirow[t]{2}{*}{ PCS* (Joule) } & \multicolumn{3}{|c|}{ Energia consumida (Joule) } & \multicolumn{2}{|c|}{ Energia (\%) } \\
\hline & Entrada & Saída & & $\begin{array}{c}\text { Águal } \\
\text { livre }(>30 \%)\end{array}$ & $\begin{array}{c}\text { Água } \\
\text { adesão }(<30 \%)\end{array}$ & Total & Entrada & Saída \\
\hline Lenha & 76.641 & & $1,96 \times 10^{7}$ & & & & 100 & \\
\hline Água & & 31.301 & & $3,7 \times 10^{10}$ & $5,8 \times 10^{10}$ & $9,5 \times 10^{10}$ & & 9 \\
\hline Carvão & & 12.723 & $2,81 \times 10^{7}$ & & & & & 36 \\
\hline Perdas & & 32.617 & & & & & & 55 \\
\hline Total & 76.641 & 76.641 & - & - & - & - & 100 & 100 \\
\hline
\end{tabular}

*PCS - Poder Calorífico Superior.

maiores que o rendimento em carvão vegetal 36\% (56 MDC). Observam-se nos resultados da conversão de massa em energia que as perdas foram maiores que os ganhos, porém as perdas de energia não estão diretamente relacionadas ao tipo de forno, mas a alguns parâmetros como a umidade da lenha e o controle do processo de carbonização. De acordo com Guimarães Neto (2007), que avaliou econômica e financeiramente o projeto de um forno retangular de 40 estéreos, esse apresenta boa rentabilidade, porque o investimento nele foi menor, por isso o retorno é maior; ainda, o preço de venda do metro de carvão é viável quando comparado com o de outros sistemas de produção de carvão vegetal.

\section{CONCLUSÕES}

Entre as técnicas adotadas na produção de carvão vegetal, a rotina 2, caracterizada pelo uso das câmaras de combustão externa, é mais eficiente no controle da carbonização.

A instrumentação do forno é uma técnica viável para a obtenção do perfil térmico da carbonização e do resfriamento, buscando definir parâmetros para o processo de produção de carvão vegetal em fornos retangulares; para tanto, é importante que a instrumentação seja adequada à ação do processo de carbonização para caracterizar, com precisão, o fenômeno de produção de carvão vegetal.

No balanço de massa e energia, verificou-se que as perdas foram maiores que os ganhos em produção, devido à elevada umidade da lenha e ao controle do processo de carbonização.

Revista Árvore, Viçosa-MG, v.35, n.4., p.949-955, 2011

\section{REFERENCIAS}

ALMEIDA, M.R. Recuperação de alcatrão em fornos de alvenaria. Produção e utilização de carvão vegetal. Belo Horizonte, Fundação Centro Tecnológico de Minas GeraisCETEC.p177-180. 1982.

ASSOCIAÇÃO BRASILEIRA DE NORMAS TÉCNICAS - ABNT. NBR 6923/81, NBR 5734/83, NBR 8112/83. Rio de janeiro: 1981.

ASSOCIAÇÃO BRASILEIRA DE NORMAS

TÉCNICAS - ABNT. NBR 6923/81, NBR 5734/83, NBR 8112/83, NBR 7190/97, NBR 11491/03. Rio de Janeiro.

\section{AMERICAN SOCIETY FOR TESTING AND}

MATERIALS. ASTM D-2015-66, ASTM

D-167-73, D-1762-64, Philadelphia, PA: American Society for Testing and Materials.

BOTREL, M. C. G; TRUGILHO, F. P.; ROSADO, S.C.S; SILVA, J. R. M. Melhoramento genético das propriedades do carvão vegetal de Eucalyptus. Revista Árvore, v.31, n.3, p.391-398, 2007.

BRITO, J. O. Expressão da produção florestal em unidades energéticas. In: 7 Congresso Florestal Brasileiro e I Congresso Florestal Panamericano, Curitiba, 19-24/setembro/1993. Anais, SBS, SBEF, Curitiba, p.280-282, 1993.

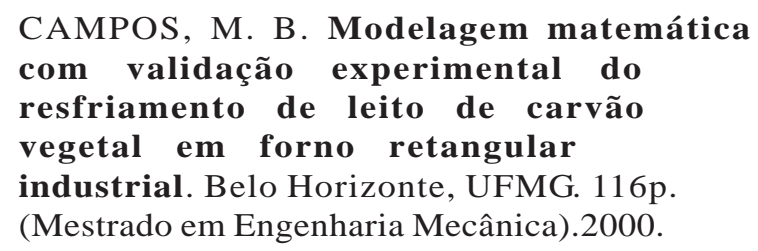


GUIMARÃES NETO, R. M. et. al. Avaliação econômica e financeira de projetos de fornos dos tipos Container industrial e retangular de 40 estéreos. Revista. Árvore, Viçosa-MG, v.31, n.4, p.709-715, 2007.

KOLLMANN, F.F.P., KUENZI, E.W., STAMM, A.J. Principles of wood science and technology. Springer-Verlag, New York, 1975, vols. 691 p.

PANSHIN, A.J. \& DeZEEUW, C.D. Textbook of wood technology. McGraw Hill, New York, 1970, vol. 1, 390 p.
SKAAR, G. Water in wood. Syracuse University Press, Syracuse, 1972, 212 p.

VALENTE, A.F. Carbonização de Madeira de Eucalipto. Informe Agropecuário 141: p. 74-79. 1986.

ZUCHI, P. S. Avaliação Ergonômica do trabalho na atividade de carvoejamento. IN: $1^{\circ}$. Simpósio Brasileiro sobre ergonomia e segurança do trabalho florestal e agrícola. Belo Horizonte-MG. 2000. 
